selection and hyperparameter optimisation. The Sequential Model-Based Optimization procedure was used to automatically select the best model configuration amongst 10 feature selection filters, 2 class imbalance correction techniques, 3 data cleaning methods and 4 classification algorithms along with their respective hyperparameters. Model optimisation was performed using a 10-fold Cross Validation (CV) while a 10 times repeated 10-fold CV was used for the predictive performance evaluation. Receiver operating characteristic $(\mathrm{ROC})$ and precision recall $(\mathrm{PR})$ curves were used to directly compare the classification potential of molecular approaches.

Results: 12,035 gene expression features and 714,486 methylation features were available for classifier building after quality control in our early arthritis B-lymphocyte dataset. Performance estimation showed the expression profile of B-lymphocytes alone to have no significant discriminatory utility for RA in this setting (average area under [AU] ROC 0.48). Methylation profiles were significantly superior for discriminating RA (average AU ROC 0.71). Interestingly, when a combined trancriptome/methylome model was generated, further enhancement of discriminatory function was observed, although this was modest (AU ROC 0.74).

Conclusion: Methylation profiling of B-lymphocytes affords better discrimination for RA than does transcriptional profiling. This may differ in other cell types. Combining data from molecular platforms may be an optimal approach. Functional analyses of the resultant B-lymphocyte signatures may yield insight into molecular pathobiology.

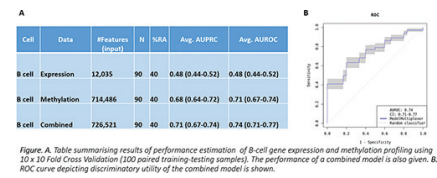

Acknowledgement: Versus Arthritis Centres of Excellence for Rheumatoid Arthritis Pathogeneisis and Genetics

Disclosure of Interests: Najib Naamane: None declared, Nishanthi Thalayasingam: None declared, Nisha Nair: None declared, Alexander Clar: None declared, Amy Anderson: None declared, Dennis Lendrem: None declared, Louise Reynard: None declared, Stephen Eyre: None declared, Anne Barton: None declared, John Isaacs Grant/research support from: Pfizer, Grant/research support from: Pfizer, Consultant for: Abbvie, Pfizer, Roche, Galvani, Merck, Gilead, Eli Lilly, Amgen, Janssen, Celltrion, NAPP, Consultant for: Abbvie, Pfizer, Roche, Galvani, Merck, Gilead, Eli Lilly, Amgen, Janssen, Celltrion, NAPP, Speakers bureau: Abbvie, Pfizer, Eli Lilly, Speakers bureau: Abbvie, Pfizer, Eli Lilly, Arthur Pratt Grant/ research support from: Dr. Pratt is in receipt of an externally peerreviewed Investigator Initiated Research grant from Pfizer (£66,000)., Grant/research support from: Dr. Pratt is in receipt of an externally peerreviewed Investigator Initiated Research grant from Pfizer (£66,000)., Speakers bureau: Dr Pratt has received honoraria from Eli Lilly and Janssen-Cilag Ltd. for his time in preparing presentations for non-promotional meetings that have been paid directly to Newcastle University., Speakers bureau: Dr Pratt has received honoraria from Eli Lilly and Janssen-Cilag Ltd. for his time in preparing presentations for non-promotional meetings that have been paid directly to Newcastle University. DOI: 10.1136/annrheumdis-2019-eular.7074

\section{FRI0010 TCR-CD3Z GENE EXPRESSION PROFILE IN A COHORT OF PATIENTS WITH RHEUMATOID ARTHRITIS}

Abeer Abdelati ${ }^{1}$, Rehab Elnemr ${ }^{2}$, Ahmed Shaaban ${ }^{1}$, Marwa Gamal ${ }^{3} .{ }^{1}$ Internal Medicine Department - Rheumatology and Clinical Immunology Unit - Faculty of Medicine - Alexandria University, Alexandria, Egypt, ${ }^{2}$ Department of Physical Medicine Rheumatology and Rehabilitation- Faculty of Medicine - Alexandria University, Alexandria, Egypt, ${ }^{3}$ Faculty of Medicine - Alexandria University, Department of Clinical and Chemical Pathology, Alexandria, Egypt

Background: Advances in understanding the pathogenesis of RA support the contribution of $T$ cells in the disease process through the recognition of the arthritogenic antigen $(\mathrm{Ag})$ and maintenance of chronic inflammatory response [1].

Previous gene association studies have demonstrated that CD247 gene expressions are associated with a variety of autoimmune disease. As regard Rheumatoid Arthritis (RA), this relationship has not been fully clarified yet.
Objectives: We aimed to evaluate the T-cell receptor-CD3 zeta chain (TCR-CD3 $\zeta$ ) gene expression profile in a cohort of patients with RA.

Methods: A case-control study on 150 consecutive RA patients diagnosed according to 2010 ACR/EULAR criteria and 150 matched healthy controls without family history of RA or other autoimmune diseases. RA patients with other autoimmune diseases, viral hepatitis B or C, malignancy or hematological disorders were excluded from the study.

All participants were subjected to history taking, clinical examination, assessment of disease activity (in RA patients) using DAS-28 and $H A Q$, routine laboratory investigations, inflammatory markers level, serological

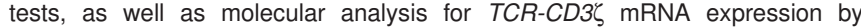
quantitative real-time polymerase chain reaction.

Results: TCR-CDЗל gene expression was significantly lower in RA cases than in healthy controls $(\mathrm{p}<0.05)$ (Table 1). Expression of TCR-CD3C revealed a significant negative correlation with RA disease duration, RF, and ESR $(p<0.05)$ in RA cases. The level of TCR-CD3G also showed a significant lower expression in +ve RF patients than in -ve RF patients $(\mathrm{p}<0.05)$. The AUC of TCR-CD3C level showed a moderate level of accuracy (AUC $=0.840, p=0.025$ ) (Figure 1), and the calculated cutoff value $(\leq 0.077)$ can precisely discriminate subjects with RA from those without RA with $93.5 \%$ sensitivity and $75 \%$ specificity(Table 2).

Table 1. Comparison between RA cases and control group as regard CD247 (mRNA levels for TCR-CD3 $\zeta$ gene expression)

\begin{tabular}{|c|c|c|c|c|}
\hline TCR-CD3 $\zeta$ & $\begin{array}{l}\text { RA cases } \\
(n=150)\end{array}$ & $\begin{array}{l}\text { Healthy Controls } \\
\qquad(n=150)\end{array}$ & $\begin{array}{l}\text { Test of } \\
\text { sig. }\end{array}$ & $\mathbf{P}$ \\
\hline $\begin{array}{l}\text { Min. - Max. } \\
\text { Mean } \pm \text { SD. } \\
\text { Median (Q1- } \\
\text { Q3) }\end{array}$ & $\begin{array}{c}0.037-12.467 \\
0.663 \pm 1.90 \\
0.178(0.109- \\
0.314)\end{array}$ & $\begin{array}{c}0.034-11.314 \\
0.816 \pm 1.64 \\
0.315(0.198- \\
0.922)\end{array}$ & $Z=-3.047^{*}$ & $0.002^{*}$ \\
\hline
\end{tabular}

Table 2. Analysis of ROC curve for TCR-CD3 $\zeta$ level as a predictor of RA (high RF)

\begin{tabular}{|c|c|c|c|c|c|c|c|c|}
\hline Variable & $\begin{array}{c}\text { Cutoff } \\
\text { point } \\
\text { (ng/ } \\
\mathrm{ml})\end{array}$ & AUC & $\mathbf{P}$ & $\begin{array}{c}\text { Sensitivity } \\
(\%)\end{array}$ & $\begin{array}{c}\text { Specificity } \\
(\%)\end{array}$ & PPV & NPV & $\begin{array}{c}\text { Accuracy } \\
(\%)\end{array}$ \\
\hline $\begin{array}{l}\text { TCR- } \\
\text { CD3 }\end{array}$ & $\begin{array}{c}\leq \\
0.077\end{array}$ & $0.840^{*}$ & $0.025^{\star \star}$ & 93.5 & 75.0 & 78.9 & 92.0 & 84.3 \\
\hline
\end{tabular}

AUC: Area under the curve

${ }^{*} \mathrm{AUC} \geq 0.5$

** Statistically significant at $p \leq 0.05$

PPV: Positive Predictive Value

NPV: Negative Predictive Value

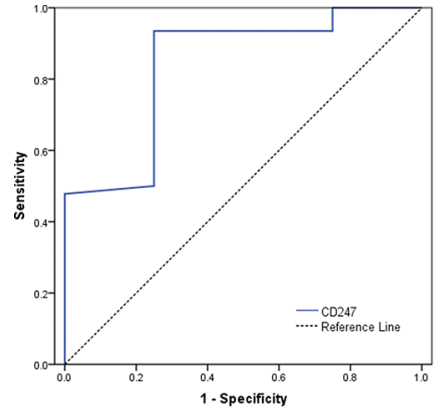

Figure 1. ROC curve for $\mathrm{CD} 247$ (TCR-CD3ל) level as a predictor of Rheumatoid arthritis

Conclusion: Our results demonstrated a lower expression of TCR-CD3 $\zeta$ in RA patients than in healthy controls. We suggested that CD247 gene down-regulation might contribute in the susceptibility to RA and help understanding the mechanisms responsible for deficient $\mathrm{T}$-cell responses in RA patients.

\section{REFERENCE:}

[1] Wfeyand CM, Gaoronzy JJ. Pathogenesis of rheumatoid arthritis. Med Clin North Am 1997; 81:29-55.

Disclosure of Interests: None declared DOI: 10.1136/annrheumdis-2019-eular.379 